\title{
Computational Study of the Kinetics of Hydrogen Abstraction from Fluoromethanes by the Hydroxyl Radical
}

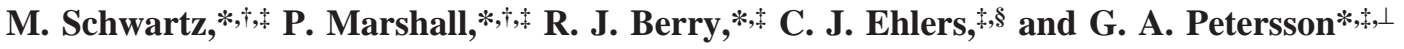 \\ Department of Chemistry, University of North Texas, Denton, Texas 76203; Center for \\ Computational Modeling Research on Nonstructural Materials, Air Force Research Laboratory, \\ Wright-Patterson AFB, Ohio 45433; and Hall-Atwater Laboratories of Chemistry, \\ Wesleyan University, Middletown, Connecticut 06459
}

Received: May 19, 1998; In Final Form: October 5, 1998

\begin{abstract}
One of the fastest steps in the initial decomposition of HFCs under combustion conditions is hydrogen atom abstraction by hydroxyl radicals. We have utilized ab initio quantum mechanics and transition-state theory (TST) to calculate the temperature dependence of rate constants for the reactions of $\mathrm{OH}$ with $\mathrm{CH}_{4}, \mathrm{CH}_{3} \mathrm{~F}$, $\mathrm{CH}_{2} \mathrm{~F}_{2}$, and $\mathrm{CHF}_{3}$. Rate constants calculated using $\mathrm{HF} / 6-31 \mathrm{G}(\mathrm{d})$ frequencies and MP2(full)/6-31G(d) structures to evaluate reactant and transition-state partition functions and the Hartree-Fock imaginary frequency, $\omega_{\mathrm{i}}$, to compute Eckart tunneling factors, $\Gamma$, yielded rate constants that were substantially greater than experiment. Adjustment of the energy barrier to effect agreement between experimental and calculated rate constants at $298 \mathrm{~K}$ gave Arrhenius plots that exhibited markedly greater curvature than measured rate constants. When the imaginary frequency and barrier height were calculated by fitting high-level (G2) energies along the reaction path with a semiempirical Eckart function, it was found that the calculated imaginary frequency is a factor of 2.5 lower than the $\mathrm{HF} / 6-31 \mathrm{G}(\mathrm{d})$ value, indicating that the energy barrier is considerably broader than predicted by the latter frequency. When the new imaginary frequencies and barrier heights were used to calculate rate constants, it was found that $k_{\mathrm{TST}}<k_{\text {expt }}$ but that lowering the barrier height (by an average of $4.7 \mathrm{~kJ} / \mathrm{mol}$ for the four reactions) yields calculated rate constants that are in excellent agreement with experiment at all temperatures.
\end{abstract}

\section{Introduction}

Halons (bromofluorocarbons), including $\mathrm{CF}_{3} \mathrm{Br}$, are excellent fire suppression agents. However, it has been well documented in recent years that these species efficiently catalyze destruction of stratospheric ozone, ${ }^{1,2}$ hence, their further commercial production has been severely restricted. ${ }^{1,3}$ Hydrofluorocarbons (HFCs) have a diminished ozone depletion; therefore, these compounds have been proposed as transitional replacements for the perhalogenated halons. ${ }^{4,5}$

Evaluation of the efficacy of these compounds to serve as alternative fire suppressants is aided by high-temperature computational kinetic modeling of the interactions of HFCs and their decomposition products with the species present in hydrocarbon fires. The reliability of this modeling is critically dependent upon the accuracy of estimated rate constants for the various reactions involving these species under combustion conditions (typically above $2000 \mathrm{~K}$ ). Unfortunately, the required kinetic data are often unavailable or else have been measured only at temperatures below $1000 \mathrm{~K}$.

One of the most important species responsible for flame propagation is the hydroxyl radical, which can also act to initiate decomposition of the proposed extinguishment agent via hydrogen atom abstraction:

\footnotetext{
$\dagger$ University of North Texas.

Air Force Research Laboratory.

$\S$ Present address: Department of Chemistry, University of North Carolina, Chapel Hill, NC 27599.

${ }^{\perp}$ Wesleyan University.
}

$$
\mathrm{CH}_{x} \mathrm{~F}_{y}+\mathrm{OH} \rightarrow \mathrm{CH}_{x-1} \mathrm{~F}_{y}+\mathrm{H}_{2} \mathrm{O}
$$

In this investigation, we have utilized ab initio quantum mechanics and canonical transition-state theory (TST) to calculate the rate constants for hydrogen abstraction from methane and the three hydrogen-containing fluoromethanes at temperatures ranging from 250 to $2000 \mathrm{~K}$. The computational methods, results, and comparison to experimental rate constants are presented below. One goal is to test methodologies that could be applied to larger molecules, such as the potential fire suppression agent heptafluoropropane.

\section{Computational Methods}

$\mathrm{Ab}$ initio molecular orbital calculations were performed on Cray-C90, SGI-Power Challenge, and HP-PARisk computers using the Gaussian suite of programs. ${ }^{6,7}$ TST rate constant computations were performed using a FORTRAN program written by the authors.

The reactants and products were characterized using the Gaussian-2 (G2) ${ }^{8}$ method. Calculations using the related G2$(\mathrm{MP} 2)^{9}$ and $\mathrm{G} 2(\mathrm{ZPE}=\mathrm{MP} 2)^{10}$ procedures gave similar results and, therefore, will not be discussed further.

Transition-state geometries were optimized at the UHF/631G(d) and UMP2(full)/6-31G(d) levels and verified to be firstorder saddle points by observation of a single imaginary frequency. The intrinsic reaction coordinate (IRC) ${ }^{11}$ was then determined using UMP2(full)/6-31G(d) calculations at increments of approximately $0.10 \mathrm{bohr} \mathrm{amu}^{1 / 2}$. Single-point G2 energies, which were designed to approximate the QCISD(T)/ $6-311+\mathrm{G}(3 \mathrm{df}, 2 \mathrm{p})$ level, were calculated at selected points along the IRC. 
TABLE 1: Selected Transition-State Geometric Parameters and Vibrational Frequencies ${ }^{a, b}$

\begin{tabular}{|c|c|c|c|c|}
\hline parameter & $\mathrm{H}_{3} \mathrm{C} \cdot \cdot \mathrm{H} \cdot \cdot \mathrm{OH}$ & $\mathrm{H}_{2} \mathrm{FC} \cdot \cdot \mathrm{H} \cdot \cdot \mathrm{OH}$ & $\mathrm{HF}_{2} \mathrm{C} \cdot \cdot \mathrm{H} \cdot \cdot \mathrm{OH}$ & $\mathrm{F}_{3} \mathrm{C} \cdot \cdot \mathrm{H} \cdot \bullet \mathrm{OH}$ \\
\hline$R(\mathrm{C} \cdot \cdot \mathrm{H})$ & $\begin{array}{l}1.226 \\
(1.313)\end{array}$ & $\begin{array}{l}1.224 \\
(1.311)\end{array}$ & $\begin{array}{l}1.222 \\
(1.312)\end{array}$ & $\begin{array}{l}1.243 \\
(1.334)\end{array}$ \\
\hline$R(\mathrm{H} \cdot \bullet \mathrm{O})$ & $\begin{array}{l}1.269 \\
(1.200)\end{array}$ & $\begin{array}{l}1.274 \\
(1.196)\end{array}$ & $\begin{array}{l}1.271 \\
(1.186)\end{array}$ & $\begin{array}{l}1.229 \\
(1.155)\end{array}$ \\
\hline$\Theta(\mathrm{CHO})$ & $\begin{array}{l}168.5 \\
(175.9)\end{array}$ & $\begin{array}{l}158.6 \\
(171.0)\end{array}$ & $\begin{array}{l}160.6 \\
(174.9)\end{array}$ & $\begin{array}{l}163.1 \\
(171.1)\end{array}$ \\
\hline$\Phi(\mathrm{HO} \cdot \cdot \mathrm{CX})^{c}$ & $\begin{array}{l}0.0 \\
(60.4)\end{array}$ & $\begin{array}{l}0.0 \\
(0.0)\end{array}$ & $\begin{array}{l}15.5 \\
(78.9)\end{array}$ & $\begin{array}{l}0.0 \\
(0.0)\end{array}$ \\
\hline $10^{46}\left(I_{A} I_{B} I_{C}\right)^{1 / 3 d}$ & 0.530 & 8.717 & 15.58 & 21.61 \\
\hline frequencies $^{e}$ & 43(IR), 343 & $108,140($ IR) & 40(IR), 118 & 79(IR), 101 \\
\hline & $347,495,867$ & $323,512,768$ & $158,452,543$ & $106,346,493$ \\
\hline & $1097,1184,1392$ & $1097,1097,1194$ & $797,1028,1129$ & $493,715,778$ \\
\hline & $1411,1445,2899$ & $1203,1450,1502$ & $1168,1198,1362$ & $998,1119,1267$ \\
\hline & $3014,3017,3608$ & $2936,3029,3604$ & $1502,2991,3602$ & $1283,1497,3601$ \\
\hline
\end{tabular}

${ }^{a}$ Bond lengths in angstroms, angles in degrees, and frequencies in wavenumbers. ${ }^{b}$ The top number in each entry is the MP2/6-31G(d) parameter. The second number (in parentheses) is the HF/6-31G(d) parameter. ${ }^{c} \mathrm{X}=\mathrm{F}$ except for $\mathrm{H}_{3} \mathrm{C} \cdot \cdot \mathrm{H} \cdot \cdot \mathrm{OH}$. ${ }^{d}$ From the MP2/6-31G(d) geometries, in kg $\mathrm{m}^{2} .{ }^{e} \mathrm{HF} / 6-31 \mathrm{G}(\mathrm{d})$ frequencies, scaled by 0.8929 . The frequency of the internal rotation (torsion) is denoted by (IR). Excludes the reaction coordinate's imaginary frequency (see Table 2).

Rate constants were evaluated using the standard Eyring TST expression: ${ }^{12}$

$$
k_{\mathrm{TST}}=\Gamma \frac{k_{\mathrm{B}} T}{h} \frac{Q_{\mathrm{TS}}}{Q_{\mathrm{Rct}}} \mathrm{e}^{-\Delta E_{\mathrm{e}}^{\ddagger} / R T}
$$

in which $\Delta E_{\mathrm{e}}^{\ddagger}$ is the classical energy barrier (excluding ZPE), $Q_{\mathrm{TS}}$ and $Q_{\mathrm{Rct}}$ are the partition functions of the transition state and reactants, and $\Gamma$ is a tunneling factor. The partition functions were evaluated using MP2(full)/6-31G(d) moments of inertia and HF/6-31G(d) frequencies (scaled by 0.8929) using standard formulas. ${ }^{13}$ The electronic partition function of the $\mathrm{OH}$ radical was evaluated using the experimental splitting of $139.7 \mathrm{~cm}^{-1}$ in the ${ }^{2} \Pi$ ground state. ${ }^{14}$ The ground electronic level of the transition state was assumed to be a degenerate doublet. Vibrations were treated as harmonic oscillators with the exception of the $\mathrm{X}_{3} \mathrm{C} \cdot \cdot \mathrm{H} \cdot \cdot \mathrm{OH}$ torsional mode of the transition state, which was treated as a hindered internal rotor using the new polynomial expression proposed by Ayala and Schlegel ${ }^{15}$ to compute $Q_{\mathrm{HR}}$. There are at least two ways to determine the reduced moment of inertia, $I_{\mathrm{r}}$, required to evaluate this partition function. In one method, proposed by Truhlar, ${ }^{16}$ the internal rotation axis is adjusted to require cancellation of the internal angular moment of the two groups. However, application of this procedure (as implemented in a subroutine of the POLYRATE program ${ }^{17,18}$ ) yielded effective internal rotation axes lying as much as $80^{\circ}$ away from the $\mathrm{C} \cdot \cdot \mathrm{H} \cdot \cdot \mathrm{O}$ axis. Therefore, we chose instead to utilize the intuitively straightforward method in which the $\mathrm{X}_{3} \mathrm{C}$ and $\mathrm{O}-\mathrm{H}$ group moments are calculated about the approximately linear $\mathrm{C} \cdot \cdot \mathrm{H} \cdot \bullet \mathrm{O}$ axis. This yields $I_{\mathrm{r}}=1.20 \times 10^{-47} \mathrm{~kg} \mathrm{~m}^{2}$ for the $\mathrm{CH}_{4}$ reaction and a nearly constant value of $I_{\mathrm{r}}=1.46 \times 10^{-47} \mathrm{~kg} \mathrm{~m}^{2}$ for reactions of the three fluoromethanes.

The tunneling factor, $\Gamma$, was evaluated using an Eckart potential function, ${ }^{19}$ which yields an analytical expression for the transmission coefficient that can then be integrated to obtain $\Gamma{ }^{20}$ The Eckart potential is a function of both the forward and reverse energy barriers, $V_{1}$ and $V_{2}$, including ZPE; thus, $V_{1}=$ $\Delta E_{\mathrm{o}}^{\ddagger}=\Delta E_{\mathrm{e}}^{\ddagger}+\mathrm{ZPE}(\mathrm{TS})-\mathrm{ZPE}(\mathrm{Rct})$. The potential also depends on the reaction coordinate corresponding to the barrier maximum, $x_{0}$, and a parameter characterizing the barrier width, $\Delta$, and is given by

$$
V(x)=\frac{A \mathrm{e}^{\left(x-x_{0}\right) / \Delta}}{\left[1+\mathrm{e}^{\left(x-x_{0}\right) / \Delta}\right]^{2}}+\frac{B \mathrm{e}^{\left(x-x_{0}\right) / \Delta}}{1+\mathrm{e}^{\left(x-x_{0}\right) / \Delta}}
$$

where $A=\left[\left(V_{1}\right)^{1 / 2}+\left(V_{2}\right)^{1 / 2}\right]^{2}$ and $B=V_{2}-V_{1}$. The width parameter is related to the imaginary frequency, $\omega_{\mathrm{i}}$, via the relations

$$
\omega_{\mathrm{i}}=\frac{1}{2 \pi c} \sqrt{\frac{f}{\mu}}, \quad f=-\frac{\left[B^{2}-A^{2}\right]^{2}}{8 A^{3} \Delta^{2}}
$$

where $f$ and $\mu$ are the vibration's force constant and reduced mass.

Initial tunneling calculations were performed using the $\mathrm{HF}$ / 6-31G(d) imaginary frequency and barriers determined from G2 energies of the reactants and products and at the maximum in the MP2(full)/6-31G(d) IRC. As discussed below, this procedure yielded unrealistic values of $\Gamma$, leading to an alternative method for determination of the tunneling factor.

\section{Results and Discussion}

Transition-State Geometries. Selected transition-state geometric parameters for the four reactions are presented in Table 1. Also shown in the table are the inertia products and scaled frequencies required for evaluation of the transition-state partition functions. Reactant energies, geometries, and frequencies, required for the calculations, are published elsewhere; ${ }^{21}$ the product energies (including zero-point energies), which are needed to evaluate the reverse energy barrier (required for the tunneling calculation), have also been calculated. ${ }^{22}$

One observes from the table that the MP2(full)/6-31G(d) values of $R(\mathrm{C} \cdot \cdot \mathrm{H})$ and $R(\mathrm{H} \cdot \cdot \mathrm{O})$ are shorter and longer, respectively, than the HF/6-31G(d) bond lengths (in parentheses) for all reactions. There have been a number of earlier studies of the transition-state geometries and kinetics of the $\mathrm{CH}_{4}+\mathrm{OH}$ reaction, utilizing a variety of basis sets. ${ }^{23-27}$ The results found here are consistent with the previous investigations, in which earlier transition states were reported for the correlated energy geometries. One observes also that, as reported earlier for the $\mathrm{CH}_{4}$ reaction, the $\mathrm{C} \cdot \cdot \mathrm{H} \cdot \mathrm{O}$ angle's deviation from linearity in all four transition states is somewhat greater when electron correlation is included in the optimization. The earlier reported changes in the $\mathrm{H}_{3} \mathrm{C} \cdot \cdot \mathrm{H} \cdot \cdot \mathrm{OH}$ transition-state geometry, from staggered to eclipsed with the inclusion of electron correlation, ${ }^{18-22}$ are also found here. However, this trend does not extend to all members of the fluoromethane series since, as seen in the table, one finds eclipsed conformations at both the HF and MP2 levels for the $\mathrm{H}_{2} \mathrm{FC} \cdot \cdot \mathrm{H} \cdot \cdot \mathrm{OH}$ and $\mathrm{F}_{3} \mathrm{C} \cdot \cdot \mathrm{H} \cdot \cdot \mathrm{OH}$ transi- 
TABLE 2: Transition-State Energies, Classical Energy Barriers, and Imaginary Frequencies ${ }^{a}$

\begin{tabular}{|c|c|c|c|c|c|c|c|}
\hline \multirow[b]{2}{*}{ reaction } & \multirow[b]{2}{*}{$E(\mathrm{G} 2)^{b}$} & \multicolumn{3}{|c|}{$\Delta E_{\mathrm{e}}^{\neq}$} & \multicolumn{3}{|c|}{$\omega_{\mathrm{i}}$} \\
\hline & & $\overline{\mathrm{G} 2 / \mathrm{MP} 2(\max )^{c, d}}$ & $\mathrm{Eck}^{c, e}$ & RT fit ${ }^{c, f}$ & $\mathrm{HF} / 6-31 \mathrm{G}(\mathrm{d})^{g}$ & Eck & adj \\
\hline $\mathrm{CH}_{4}+\mathrm{OH}$ & -116.092559 & $\begin{array}{c}31.2 \\
{[82.9]}\end{array}$ & $\begin{array}{c}34.2 \\
(3.0)\end{array}$ & $\begin{array}{c}27.4 \\
(-6.8)\end{array}$ & $2836 \mathrm{i}$ & $1165 \mathrm{i}$ & $1084 \mathrm{i}$ \\
\hline $\mathrm{CH}_{3} \mathrm{~F}+\mathrm{OH}$ & -215.233865 & $\begin{array}{c}24.6 \\
{[91.1]}\end{array}$ & $\begin{array}{c}27.0 \\
(2.4)\end{array}$ & $\begin{array}{c}21.5 \\
(-5.5)\end{array}$ & $2872 \mathrm{i}$ & $1175 \mathrm{i}$ & $986 \mathrm{i}$ \\
\hline $\mathrm{CH}_{2} \mathrm{~F}_{2}+\mathrm{OH}$ & -314.391201 & $\begin{array}{c}25.4 \\
{[91.6]}\end{array}$ & $\begin{array}{c}28.7 \\
(3.3)\end{array}$ & $\begin{array}{c}26.2 \\
(-2.5)\end{array}$ & $2942 \mathrm{i}$ & $1375 \mathrm{i}$ & $1162 \mathrm{i}$ \\
\hline $\mathrm{CHF}_{3}+\mathrm{OH}$ & -413.556555 & $\begin{array}{c}37.1 \\
{[83.4]}\end{array}$ & $\begin{array}{c}37.2 \\
(0.1)\end{array}$ & $\begin{array}{c}33.2 \\
(-4.0)\end{array}$ & $3023 \mathrm{i}$ & $1382 \mathrm{i}$ & $1196 \mathrm{i}$ \\
\hline avg change & & & +2.2 & -4.7 & & & \\
\hline std deviation & & & 1.3 & 1.6 & & & \\
\hline
\end{tabular}

${ }^{a}$ TS energies in au, energy barriers in $\mathrm{kJ} / \mathrm{mol}$, and frequencies in wavenumbers. ${ }^{b} \mathrm{G} 2$ energies do not include the ZPE. ${ }^{c}$ Classical energy barriers do not include the ZPE. ${ }^{d}$ Quantities in brackets are energy barriers for the reverse reaction. ${ }^{e}$ Quantities in parentheses represent $\Delta E_{\mathrm{e}}^{\ddagger}[$ Eck] $\Delta E_{\mathrm{e}}^{\ddagger}[\mathrm{G} 2 / \mathrm{MP} 2(\max )] .{ }^{f}$ Quantities in parentheses represent $\Delta E_{\mathrm{e}}^{\ddagger}[\mathrm{RT}$ fit $]-\Delta E_{\mathrm{e}}^{\ddagger}[\mathrm{Eck}] .{ }^{g}$ Scaled by 0.8929.

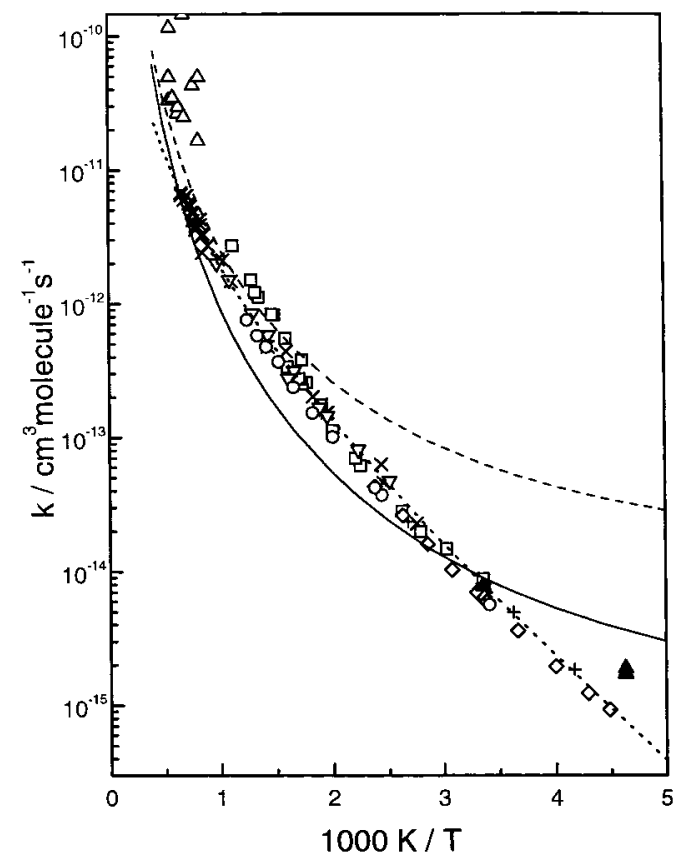

Figure 1. Temperature dependence of the rate constant for the $\mathrm{CH}_{4}$ $+\mathrm{OH}$ reaction, using the $\mathrm{HF} / 6-31 \mathrm{G}(\mathrm{d})$ imaginary frequency for tunneling calculations: dashed line, calculated rate constant using the G2 energy barrier calculated at the maximum in the MP2 IRC $\left(\Delta E^{\ddagger}=\right.$ $31.2 \mathrm{~kJ} / \mathrm{mol}$ ); solid line, calculated rate constant using barrier adjusted to fit the experimental rate constant at $298 \mathrm{~K}$; dotted line, recommended experimental curve from ref 37. Experimental points: $O$, ref $29 ; \Delta$, ref $30 ; \boldsymbol{\Delta}$, ref $31 ; \times$, ref $32 ; \nabla$, ref $33 ;+, \operatorname{Ref} 34 ; \square$, ref $35 ; \diamond$, ref 36 .

tion states. Fu et al. ${ }^{28}$ have also reported an eclipsed TS for the latter reaction at the MP2/6-311G(d,p) level.

Rate Constants. Displayed in the third column of Table 2 are the forward and reverse classical energy barriers (excluding vibrational ZPE, which is included in the vibrational partition functions) for the four reactions calculated from $\mathrm{G} 2$ energies of the reactants and products and of the MP2(full)/6-31G(d) transition states. The table also contains the HF/6-31G(d) imaginary frequencies, $\omega_{\mathrm{i}}$ (sixth column), at the transition state (required for the tunneling calculations). These parameters together with transition-state and reactant inertia products and frequencies were used to calculate the rate constants via eq 2 .

Displayed in Figure 1 is an Arrhenius plot of the temperature dependence of $k_{\text {TST }}$ for the reaction $\mathrm{CH}_{4}+\mathrm{OH}$ [dashed line], for which there is the most accurate experimental data ${ }^{29-36}$ [plotted as symbols] over the broadest range of temperatures. The dotted line in the figure represents the recommended temperature dependence of $k_{\text {expt }}$ from the review of Baulch et al. ${ }^{37}$ One sees that the calculated rate constants are considerably greater than measured values at low to moderate temperatures (by as much as an order of magnitude or more at room temperature and below). It is not uncommon to observe significant deviations of TST rate constants from experiment, which are often attributed to errors in the calculated energy barrier. Because of the exponential dependence of $k_{\mathrm{TST}}$ on $C$, an error of only $5 \mathrm{~kJ} / \mathrm{mol}$ in the barrier height would yield a value of $k_{\mathrm{TST}} / k_{\mathrm{expt}} \approx 7.5$ at room temperature (not considering changes in $\Gamma$ with barrier height).

A common remedy for this problem is to adjust the barrier height to effect equality of the calculated and experimental rates at a reference temperature (often taken to be $298 \mathrm{~K}$ ). The energy barrier was adjusted iteratively [the required recalculation of $\Gamma$ prohibits direct determination of $\delta\left(\Delta E_{\mathrm{e}}^{\dagger}\right)$ ], and it was found that $k_{\mathrm{TST}}=k_{\text {expt }}$ at $298 \mathrm{~K}$ when the ab initio barrier is increased by $8.0 \mathrm{~kJ} / \mathrm{mol}$ (to $39.2 \mathrm{~kJ} / \mathrm{mol}$ ). The calculated rate constants using the higher value of $\Delta E_{\mathrm{e}}^{*}$ are plotted in Figure 1 [solid curve]. One observes clearly from this plot that the computed rate constants exhibit markedly greater curvature over the complete temperature range than do the experimental $k$ 's. Therefore, it may be concluded that errors in $k_{\mathrm{TST}}$ cannot be attributed primarily to incorrect ab initio barrier heights.

Although not shown, comparison of calculated rate constants with experimental data for the reaction of $\mathrm{OH}$ with $\mathrm{CH}_{3} \mathrm{~F},{ }^{38-41}$ $\mathrm{CH}_{2} \mathrm{~F}_{2},{ }^{38,39,42-44}$ and $\mathrm{CHF}_{3}{ }^{38,39,41,42,44}$ exhibit the same trends; i.e., values of $k_{\mathrm{TST}}$ are significantly greater than experiment when the ab initio barriers are used and exhibit too much curvature when the barrier is raised to produce agreement between $k_{\text {TST }}$ and $k_{\text {expt }}$ at $298 \mathrm{~K}$.

A Revised Procedure. To investigate further the source(s) of error in the calculated rate constants, we decided to explore the reaction path energies at a higher level of theory. As reported by one of the authors, ${ }^{20}$ when the IRC for a reaction is determined at various levels of theory, the shape of the PES, including its breadth, peak position, and barrier height, is dependent upon the chosen basis set and level of electron correlation correction. However, the reaction path geometries are relatively insensitive to the basis set. Accordingly, one may efficiently calculate a reasonable energetically accurate highlevel IRC utilizing geometries determined at a lower level. Therefore, to obtain a better characterization of the PES, we have calculated $\mathrm{G} 2$ energies (excluding ZPE) at various points along the MP2(full)/6-31G(d) IRC for all four reactions. The results for $\mathrm{CH}_{4}+\mathrm{OH}$ are displayed in Figure 2.

The diamonds in this figure are the MP2(full)/6-31G(d) energies along the IRC computed at this level. The dashed curve represents the PES one obtains when the HF/6-31G(d) imaginary 


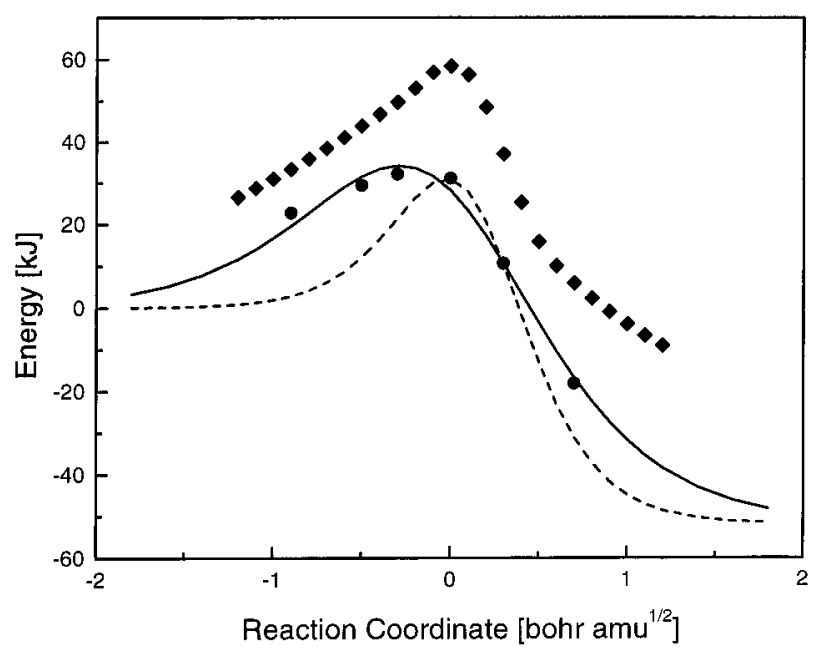

Figure 2. Potential energy diagram for the $\mathrm{CH}_{4}+\mathrm{OH}$ reaction: $\bullet$ MP2(full)/6-31G(d) IRC; 9 , G2 energies at points along the MP2 IRC; dashed line, PED calculated using the G2 energy barrier at the maximum in the MP2 IRC $\left(\Delta E^{\ddagger}=31.2 \mathrm{~kJ} / \mathrm{mol}\right)$ and the HF/6-31G(d) imaginary frequency $\left(\omega_{\mathrm{i}}=2836 \mathrm{~cm}^{-1}\right)$; solid line, PED calculated by fitting an Eckart function to the G2 energies along the IRC $\left(\Delta E^{\ddagger}=\right.$ $34.2 \mathrm{~kJ} / \mathrm{mol}$ and $\left.\omega_{\mathrm{i}}=1165 \mathrm{~cm}^{-1}\right)$.

frequency and the G2 energy at the MP2(full)/6-31G(d) maximum are used to characterize the shape and position of the energy barrier, and the circles are G2 energies (without ZPE) determined at points along the MP2 IRC. The solid curve represents the fit of an Eckart function (eqs 3) to the $\mathrm{G} 2$ energies subject to the constraint that $V_{1}-V_{2}=\Delta E_{\text {rxn }}$ (i.e., the forward and reverse barriers must be consistent with the calculated overall energy change for the reaction). The solid curve in Figure 2 is an imperfect fit to the filled circles, but a major improvement over the dashed curve, and is probably within the uncertainty of the $\mathrm{G} 2$ calculations $\left( \pm 6 \mathrm{~kJ} \mathrm{~mol}^{-1}\right)$.

One observes several significant differences in the shape of the new G2 PES compared to that of the lower level curve. In addition to a shift in the barrier maximum (which has no impact on calculated rate constants), the new barrier height is somewhat greater and the breadth of G2 IRC is substantially greater than the curve generated using $\omega_{\mathrm{i}}(\mathrm{HF})$. These differences are quantified for all four reactions in Table 2. $\Delta E_{\mathrm{e}}^{\ddagger}[\mathrm{Eck}]$ and $\omega_{\mathrm{i}}$ [Eck] are the barrier height and imaginary frequency determined by the Eckart function fit to the $\mathrm{G} 2$ energies. One finds that, in every case, the fitted barrier height is somewhat greater than the value determined at the MP2(full)/6-31(d) transition state. More significantly, the fitted imaginary frequencies, $\omega_{\mathrm{i}}[\mathrm{Eck}]$, are much lower than values of $\omega_{\mathrm{i}}[\mathrm{HF} / 6-31 \mathrm{G}(\mathrm{d})]$, by approximately a factor of 2.5 for all four reactions, indicating a much greater breadth of the higher level G2 IRC. As shown below, this large change in $\omega_{\mathrm{i}}$ has a major impact on the calculated tunneling factors, which are quite sensitive to the PES curvature.

The values of $V_{1}, V_{2}$, and $\Delta$ (and, hence, $\omega_{\mathrm{i}}$ ) obtained from a fit of the G2 energies along the reaction path characterize the classical PES without vibrational zero-point energy. However, as noted briefly above (section II), it is important to include the ZPE when calculating the tunneling factor, $\Gamma .{ }^{45}$ Therefore, $V_{1}$ and $V_{2}$ (and thus $A$ and $B$ in eq 3 ) were adjusted by adding in the ZPE's calculated for the reactants, products, and transition states, and then $\Gamma$ was evaluated as described elsewhere. ${ }^{20}$ Since the zero-point energy of the transition state for the reactions studied here is lower than for either the products or reactants, this adjustment lowers the barriers somewhat, which corresponds

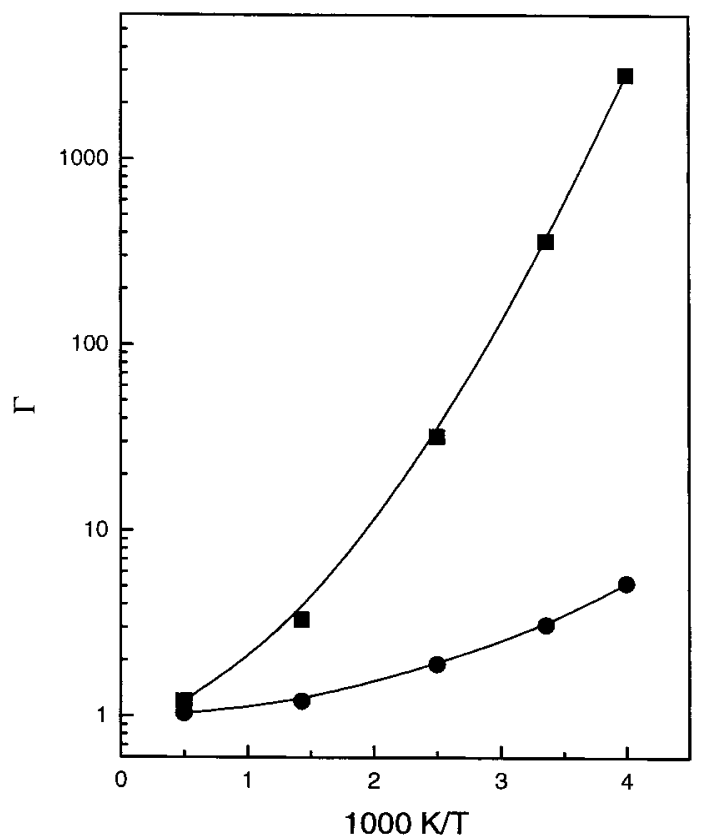

Figure 3. Tunneling factors $(\Gamma)$ for the $\mathrm{CH}_{4}+\mathrm{OH}$ reaction; calculated with the original energy barrier and Hartree-Fock imaginary frequency $\left[\omega_{\mathrm{i}}(\mathrm{HF})\right] ; \boldsymbol{\bullet}$, calculated with the fitted energy barrier and imaginary frequency $\left[\omega_{\mathrm{i}}(\right.$ Eck $\left.)\right]$.

to a lower curvature and, hence, a somewhat diminished imaginary frequency, which is shown in the last column of Table $2\left[\omega_{\mathrm{i}}(\operatorname{adj})\right]$.

Results Using the Revised Procedure. As shown in Figure 3 for the $\mathrm{CH}_{4}+\mathrm{OH}$ reaction, the effect of using the revised parameters from the higher level G2 IRC on the calculated tunneling factors is quite striking. Whereas the Hartree-Fock imaginary frequencies and barriers heights calculated at the MP2 IRC maximum yielded a change in $\Gamma$ [squares] of at least 3 orders of magnitude over the range from 250 to $2000 \mathrm{~K}$, the variation in the tunneling efficiency is a much more modest factor of $<10$ when using the fitted values of the imaginary frequency and barrier heights. Although not shown, similar dramatic decreases in the variation of $\Gamma$ were observed for reactions of the three fluoromethanes when $\omega_{\mathrm{i}}[\mathrm{HF}]$ was replaced by $\omega_{\mathrm{i}}[\mathrm{Eck}]$ in the tunneling calculation. From these results, it is clear that the excess curvature in the Arrhenius plot of the calculated rate constants (vide supra) resulted from calculated tunneling efficiencies that were far too high at the lower temperatures.

We have recalculated rate constants for the four abstraction reactions using the new fitted PES parameters from Table 2; the results are displayed in Figure 4 [dashed curves]. One observes that now $k_{\text {TST }}$ is significantly lower than $k_{\text {expt }}$ for all of the reactions, except for $\mathrm{CH}_{4}+\mathrm{OH}$ (Figure 4A) at elevated temperatures. Once again, though, assuming that the deviations are due predominantly to errors in the calculated barrier heights, the value of $\Delta E_{\mathrm{e}}^{\ddagger}$ was adjusted to require that $k_{\mathrm{TST}}=k_{\text {expt }}$ at $298 \mathrm{~K}$; the adjusted values of the barrier heights for the four reactions are given in Table $2\left(\Delta E_{\mathrm{e}}^{\dagger}[\mathrm{RT}\right.$ fit]). For reference, we include in Table 3 parameters obtained from modified "Arrhenius" fits (of the form $k=A T^{n} \mathrm{e}^{-B / T}$ ) to both calculated rate constants and experimental data on the four reactions.

As shown by the solid curves in Figure 4, the adjusted rate constants are generally in very good agreement with experiment at all temperatures for which measured rates are available. In particular, one observes that the curvatures of the calculated Arrhenius plots match the experimental data rather well, unlike 

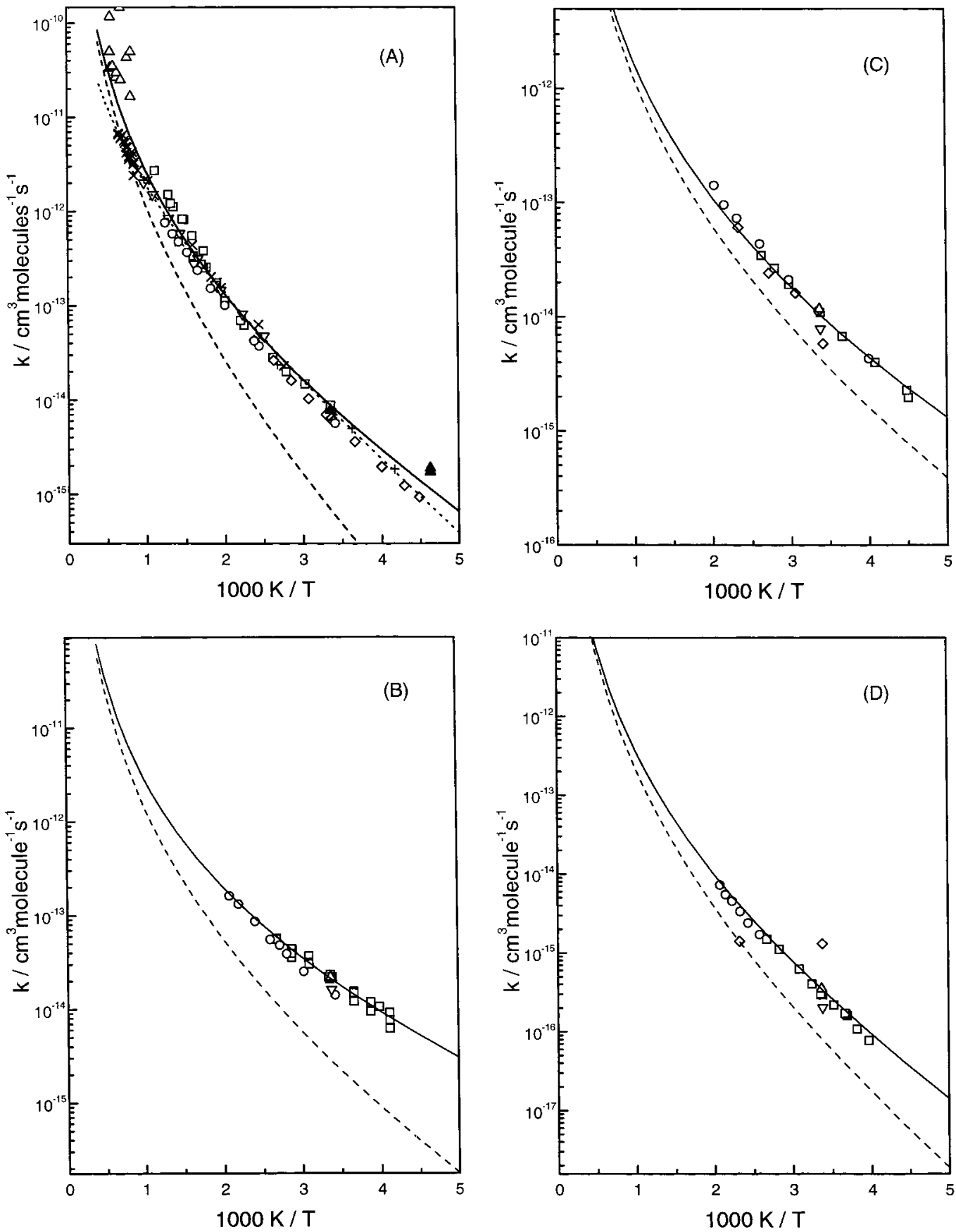

Figure 4. Temperature dependence of the rate constants for the reactions of $\mathrm{CH}_{x} \mathrm{~F}_{4-x}(x=1,4)$ with $\mathrm{OH}$, using Eckart fit imaginary frequencies for tunneling calculations. (A) $\mathrm{CH}_{4}$, (B) $\mathrm{CH}_{3} \mathrm{~F}$, (C) $\mathrm{CH}_{2} \mathrm{~F}_{2}$, (D) $\mathrm{CHF}_{3}$. Dashed line: calculated rate constant using Eckart energy barrier. Solid line: calculated rate constant using barrier adjusted to fit experimental rate constant at $298 \mathrm{~K}$. Experimental points: (A) dotted line, recommended equation from ref 37; individual points, see Figure 1 caption; (B) $\bigcirc$, ref 38; $\nabla$, ref $39 ; \Delta$, ref $40 ; \square$, ref $41 ;$ (C) $\diamond$, ref $42 ; \square$, ref $43 ; \bigcirc$, ref $38 ; \nabla$, ref $39 ; \Delta$, ref $44 ;$ (D) $\bigcirc, \operatorname{ref} 38 ; \nabla, \operatorname{ref} 39 ; \square, \operatorname{ref} 41 ; \diamond, \operatorname{ref} 42 ; \Delta$, ref 44.

the initial results using Hartree-Fock imaginary frequencies (described above). The good agreement with experiment may also be seen in Table 4 , in which values of $k_{\text {calc }}$ and the ratio $k_{\text {calc }} / k_{\text {expt }}$ (in parentheses) are displayed as a function of temperature for the four reactions.

One sees from Figure 4A and Table 4 that our calculated rate constants for hydrogen abstraction from $\mathrm{CH}_{4}$ at temperatures of around $1500 \mathrm{~K}$ and above lie between the reported measurements in refs 29 and 32 . However, they are approximately $2-3$ times larger than the recommendation of Baulch et al. ${ }^{37}$ in this temperature regime. This may reflect the importance at the highest temperatures of variational effects, which were not considered in the present study.
One finds from Table 2 that the errors in the barrier heights are systematically positive; the average decrease in barrier height required to match experiment at $298 \mathrm{~K}$ is $4.7 \pm 1.6 \mathrm{~kJ} / \mathrm{mol}$. This trend is not surprising and is in good agreement with the recent results of one of the authors, ${ }^{20}$ who recommended a general G2 energy barrier correction of $-5.2 \mathrm{~kJ} / \mathrm{mol}$ based on analysis of the $\mathrm{H}+\mathrm{H}_{2}$ reaction. That correction is rather close to the average required adjustment of $-4.7 \mathrm{~kJ} / \mathrm{mol}$ found for the four reactions studied here. In fact, our value of $\Delta E_{\mathrm{e}}^{+}[\mathrm{RT}$ fit] for the reaction of $\mathrm{CH}_{4}+\mathrm{OH}$ is only $0.1 \mathrm{~kJ} / \mathrm{mol}$ higher than the G2 value in Table IX of ref 20b. This apparently high accuracy for the empirically corrected G2 barrier height benefits from a fortuitous cancellation of errors, since we have omitted 
TABLE 3: Calculated and Experimental "Arrhenius" Fit Parameters for $k=A T^{n} \mathrm{e}^{-B / T}$

\begin{tabular}{cllccl}
\hline reaction & & \multicolumn{1}{c}{$A^{a}$} & $n$ & $B^{b}$ & \multicolumn{1}{c}{ range $^{b}$} \\
\hline $\mathrm{CH}_{4}+\mathrm{OH}$ & calc & $1.39 \mathrm{E}-21^{\mathrm{g}}$ & 3.21 & 793.1 & $200-2500$ \\
& expt $^{c}$ & $2.6 \mathrm{E}-17$ & 1.83 & 1400 & $250-2000$ \\
$\mathrm{CH}_{3} \mathrm{~F}+\mathrm{OH}$ & calc $^{d}$ & $3.78 \mathrm{E}-22$ & 3.35 & 368.3 & $200-2500$ \\
& expt $^{d}$ & $5.24 \mathrm{E}-23$ & 3.62 & 250.0 & $243-480$ \\
$\mathrm{CH}_{2} \mathrm{~F}_{2}+\mathrm{OH}$ & calc & $4.39 \mathrm{E}-22$ & 3.27 & 479.2 & $200-2500$ \\
& expt $^{e}$ & $8.56 \mathrm{E}-28$ & 5.27 & -24.9 & $222-492$ \\
$\mathrm{CHF}_{3}+\mathrm{OH}$ & calc $^{f}$ & $1.15 \mathrm{E}-23$ & 3.66 & 1066 & $200-2500$ \\
& expt $^{f}$ & $1.48 \mathrm{E}-21$ & 2.93 & 1327 & $252-480$
\end{tabular}

${ }^{a} \mathrm{In} \mathrm{cm}^{3}$ molecule $\mathrm{s}^{-1} \mathrm{~s}^{-1} \cdot{ }^{b}$ In kelvin. ${ }^{c}$ Equation parameters from ref 37. ${ }^{d}$ Parameters from fit to data in refs $38,39,40$, and $41 .{ }^{e}$ Parameters from fit to data in refs $38,39,42,43$, and $44 .{ }^{f}$ Parameters from fit to data in refs $38,39,41,42$, and $44 .{ }^{g} \operatorname{Read}$ as $1.39 \times 10^{-21}$.

TABLE 4: Temperature Dependence of Calculated Rate Constants and Comparison to Experiment ${ }^{a, b}$

\begin{tabular}{cllll}
\hline$T(\mathrm{~K})$ & $\mathrm{CH}_{4}+\mathrm{OH}$ & $\mathrm{CH}_{3} \mathrm{~F}+\mathrm{OH}$ & $\mathrm{CH}_{2} \mathrm{~F}_{2}+\mathrm{OH}$ & $\mathrm{CHF}_{3}+\mathrm{OH}$ \\
\hline 250 & $2.80 \mathrm{E}-15^{c}$ & $9.08 \mathrm{E}-15$ & $4.23 \mathrm{E}-15$ & $8.46 \mathrm{E}-17$ \\
& $(1.2)$ & $(1.0)$ & $(1.1)$ & $(1.1)$ \\
298 & $8.00 \mathrm{E}-15$ & $2.02 \mathrm{E}-14$ & $9.91 \mathrm{E}-15$ & $3.04 \mathrm{E}-16$ \\
& $(1.0)$ & $(1.0)$ & $(1.0)$ & $(1.0)$ \\
350 & $2.80 \mathrm{E}-15$ & $9.08 \mathrm{E}-15$ & $2.19 \mathrm{E}-14$ & $8.46 \mathrm{E}-17$ \\
& $(0.9)$ & $(1.0)$ & $(0.9)$ & $(1.0)$ \\
400 & $4.23 \mathrm{E}-14$ & $7.48 \mathrm{E}-14$ & $4.04 \mathrm{E}-14$ & $2.39 \mathrm{E}-15$ \\
& $(0.9)$ & $(1.0)$ & $(0.9)$ & $(1.1)$ \\
500 & $1.35 \mathrm{E}-13$ & $1.96 \mathrm{E}-13$ & $1.11 \mathrm{E}-13$ & $1.01 \mathrm{E}-14$ \\
& $(1.0)$ & $(1.1)$ & $(0.8)$ & $(1.2)$ \\
700 & $6.66 \mathrm{E}-13$ & & & \\
& $(1.2)$ & & & \\
1000 & $3.04 \mathrm{E}-12$ & & & \\
& $(1.5)$ & & & \\
1500 & $1.41 \mathrm{E}-11$ & & & \\
& $(2.1)$ & & & \\
2000 & $3.77 \mathrm{E}-11$ & & & \\
& $(2.7)$ & & & \\
exptl & $250-2000 \mathrm{~K}$ & $243-480 \mathrm{~K}$ & $222-492 \mathrm{~K}$ & $252-480 \mathrm{~K}$ \\
range & & & & \\
nand & & & &
\end{tabular}

${ }^{a}$ Rate constants in units of $\mathrm{cm}^{3}$ molecule ${ }^{-1} \mathrm{~s}^{-1} \cdot{ }^{b}$ The quantities in parentheses represent the ratio $k_{\text {cal }} / k_{\text {exp }}{ }^{c} \operatorname{Read}$ as $2.80 \times 10^{-15}$.

the effects of variations of the ZPE along the IRC. Our value calculated from addition of the ZPE to the maximum along the classical (vibrationless) IRC could be several $\mathrm{kJ} / \mathrm{mol}$ below the maximum along the vibrationally adiabatic IRC.

A procedure commonly utilized in the calculation of transition-state energies is to compute a high-level energy barrier at the maximum in a lower level IRC. As found here (Table 2), the actual G2 barrier heights $\left(\Delta E_{\mathrm{e}}^{\ddagger}[\mathrm{Eck}]\right)$ are higher than barriers obtained at the MP2 IRC maximum $\left(\Delta E_{\mathrm{e}^{*}}^{*}\right.$ $[$ G2/MP2(max)]) since the maxima of the two PESs do not coincide (Figure 2). Yet as found here and elsewhere, ${ }^{20}$ most methods, including G2, tend to overestimate the true energy barriers. Hence, the above simple procedure benefits from a fortuitous partial cancellation of error.

As discussed above, incorrect values of the reaction path's imaginary frequency form the greatest source of error in the calculation of the tunneling factor for hydrogen atom abstraction reactions since the barrier's curvature, $\partial^{2} V / \partial x^{2}$, is proportional to $\omega_{\mathrm{i}}^{2}$. In principle, a less computationally intensive procedure than fitting high-level energies along the IRC to obtain an accurate measure of PES curvature would be to perform the frequency analysis with a larger basis set and higher level treatment of electron correlation. Accordingly, we have reoptimized the $\mathrm{CH}_{4}+\mathrm{OH}$ transition state at the QCISD/6-311G$(\mathrm{d}, \mathrm{p})$ level and obtained a value of $\omega_{\mathrm{i}}=1885 \mathrm{~cm}^{-1}$. While clearly an improvement over the HF/6-31G(d) result, the higher

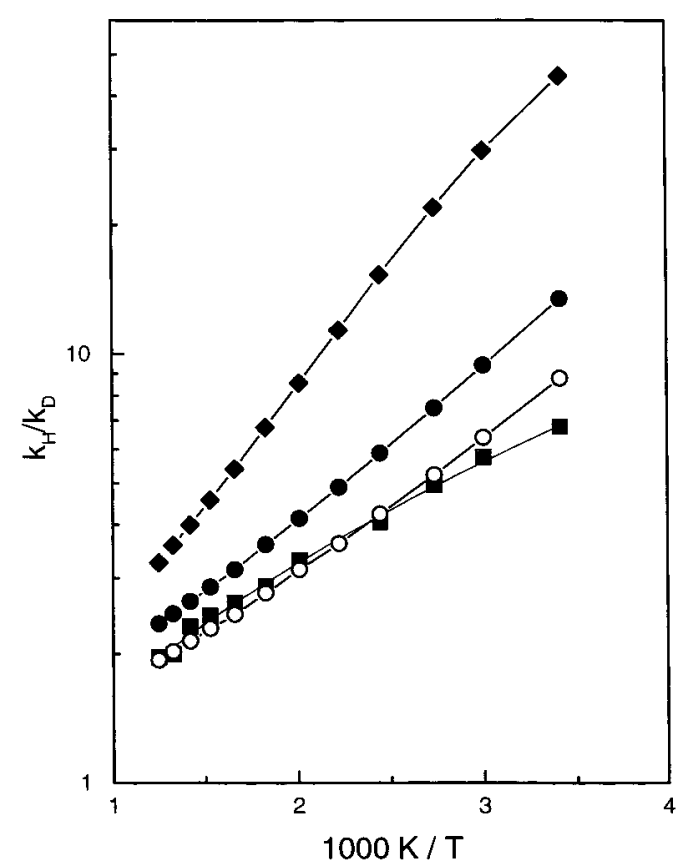

Figure 5. Kinetic isotope effect for the reaction of $\mathrm{CH}_{4}\left(\mathrm{CD}_{4}\right)$ with $\mathrm{OH}$ : filled squares, experiment; filled diamonds, computed using the $\mathrm{HF} / 6-31 \mathrm{G}(\mathrm{d})$ imaginary frequency; filled circles, computed using the Eckart fit imaginary frequency; open circles, computed using the Eckart fit imaginary frequency with a $100 \mathrm{~cm}^{-1}$ adjustment in the relative ZPE's.

level frequency is still more than $60 \%$ greater than the value obtained from the Eckart fit. This frequency yields a roomtemperature tunneling factor of approximately $\Gamma(298) \approx 20$, which is still almost an order of magnitude greater than the value obtained using the fitted frequency $(\Gamma \approx 3)$. Similarly high values of $\omega_{\mathrm{i}}(\mathrm{QCISD})$ and $\Gamma$ were obtained for reactions of the fluoromethanes. Hence, we conclude that fitting the highlevel PES is the only currently feasible procedure for calculating accurate tunneling factors.

We briefly compare our results with two recent computational studies of $\mathrm{OH}$ kinetics. Melissas and Truhlar noted that their computed rate constants for $\mathrm{OH}+\mathrm{CH}_{4}$ exhibited larger curvature in the Arrhenius plot than the experimental values. ${ }^{22}$ This can be quantified through the $T$ exponent in the modified Arrhenius expression above, where $n=3.95$ for their work; cf. $n=3.21$ (Table 3 ) in the present calculations. They noted several possible reasons, and it may be that their work yielded too high a tunneling correction. Similarly, $\mathrm{Fu}$ et al. ${ }^{28}$ investigated the reaction of $\mathrm{OH}$ with $\mathrm{CHF}_{3}$, and an Arrhenius plot of their results reveals significantly greater curvature than seen experimentally. Their MP2(full)/6-311G(d,p) imaginary frequency of $2466 \mathrm{~cm}^{-1}$ is much higher than our value of 1084 $\mathrm{cm}^{-1}$ (Table 2) and probably leads to an overestimation of tunneling.

The Kinetic Isotope Effect. For reactions involving hydrogen atom transfer, reactant deuteration has a major impact on the rate constants, yielding comparatively large kinetic isotope effects, $\mathrm{KIE}=k_{\mathrm{H}} / k_{\mathrm{D}}$ (where $k_{\mathrm{H}}$ and $k_{\mathrm{D}}$ represent the rate constants for proton and deuteron transfer). Dunlop and Tully ${ }^{29}$ have measured rate constants for the reactions of both $\mathrm{CH}_{4}$ and $\mathrm{CD}_{4}$ with $\mathrm{OH}$ and have reported experimental KIE's ranging from 6.8 at $293 \mathrm{~K}$ to 2.0 at $800 \mathrm{~K}$; their results are plotted in Figure 5 (squares).

To afford a comparison with the experimental isotope effects, we have computed the temperature dependence of the rate constant for the reaction $\mathrm{CD}_{4}+\mathrm{OH} \rightarrow \mathrm{CD}_{3}+\mathrm{HOD}$, using the 
methods detailed in previous sections. Calculated KIE's using the HF/6-31G(d) imaginary frequencies (section B) are displayed as diamonds in Figure 5. The kinetic ratios, which vary from 44 (at $293 \mathrm{~K}$ ) to 3.3 (at $800 \mathrm{~K}$ ), are much higher than the measured KIE's. This is not surprising, and results directly from the gross overestimation of the tunneling factors (vide supra), which has a greater impact on $\Gamma(\mathrm{H})$ than on $\Gamma(\mathrm{D})$. The computed KIE's improve markedly when the rate constants are calculated using the Eckart fit imaginary frequencies (section D). As displayed in the figure (filled circles), the calculated ratio varies between 13.4 and 2.4 over the temperature range for which experimental data are available.

To ascertain the source of residual errors in the computed kinetic isotope effect $[\mathrm{KIE}($ calc $) \approx 2.0 \mathrm{KIE}(\exp )$ at $293 \mathrm{~K}$ ], we have determined the individual contributions of each term in the TST expression [ $Q_{\text {trans }}, Q_{\text {rot }}, Q_{\text {vib }}, Q_{\mathrm{HIR}}, \Gamma$, and ZPE] to the computed KIE. ${ }^{46}$ Perhaps counter to one's intuitive expectation, the ratio of tunneling factors for the two reactions contributes a relatively small factor of only 1.7 to the calculated kinetic ratio at the lowest experimental temperature, and its impact diminishes rapidly at higher temperatures [e.g., $\operatorname{KIE}(\Gamma)<1.1$ at $800 \mathrm{~K}$ ]. Almost all of the other terms have equally modest contributions to the KIE. ${ }^{46}$ The sole exception to this results from the differing vibrational ZPE's for the two reactions. At the lowest temperature, $\mathrm{KIE}(\mathrm{ZPE})=5.3$. This large ratio stems from the fact that the difference in ZPE's of the transition state and reactant $\left[\triangle \mathrm{ZPE}=(\mathrm{ZPE})_{\mathrm{TS}}-(\mathrm{ZPE})_{\mathrm{Rct}}\right]$ reduces the energy barrier for the $\mathrm{CH}_{4}+\mathrm{OH}$ reaction by $4.0 \mathrm{~kJ} \mathrm{~mol}^{-1}$ more than for the $\mathrm{CD}_{4}+\mathrm{OH}$ reaction. ${ }^{47}$

The correction to the classical energy barrier from vibrational ground-state energies is a relatively small difference between two large numbers. ${ }^{47}$ Therefore, since $k_{\mathrm{TST}}$ is exponentially dependent upon the barrier height, relatively small errors in computed vibrational frequencies can yield large errors in the computed KIE. For example, if the magnitude of the ZPE correction to the $\mathrm{CH}_{4}+\mathrm{OH}$ reaction is diminished by only $100 \mathrm{~cm}^{-1}$ (or equivalently if the correction to the $\mathrm{CD}_{4}+\mathrm{OH}$ reaction is increased by this amount), then, as shown in Figure 5 (open circles), one obtains virtually quantitative agreement with the experimental kinetic isotope ratio.

This error in the computed KIE cannot be removed simply by increasing the level of vibrational frequency calculation since, as noted above, computed frequencies at the maximum in the moderate level IRC represent only an approximation to frequencies at the interpolated high-level transition state. Fortunately, this error in the computed ZPE has no effect on rate constants computed by the methods described above because the empirical adjustment of the barrier to match calculated and experimental rate constants at $298 \mathrm{~K}$ will correct for errors in both the classical energy barrier and the vibrational ZPE.

\section{Summary and Conclusions}

Transition states for the hydrogen atom abstraction reactions by the $\mathrm{OH}$ radical from $\mathrm{CH}_{4}$ and the three fluoromethanes were located at the HF/6-31G(d) and MP2(full)/6-31G(d) levels, and the MP2(full)/6-31G(d) intrinsic reaction coordinate was obtained. Rate constants initially were calculated using the Hartree-Fock frequencies and MP2 moments of inertia and G2 energy barriers calculated via the standard transition-state theory equation with the tunneling factor calculated using a onedimensional Eckart potential. Calculated rate constants were too high by approximately 1 order of magnitude at room temperature. Adjustment of the energy barrier to effect agreement between experimental and calculated rate constants at 298
$\mathrm{K}$ yielded Arrhenius plots that exhibited significantly greater curvature than measured rate constants.

Acquisition of high-level (G2) energies at various points along the IRC revealed that the breadth of the barrier is markedly greater than predicted by the HF/6-31G(d) imaginary frequency. The G2 PES was fit by an Eckart function to obtain new values for the barrier maximum and for $\omega_{\mathrm{i}}$. When these values were used to calculate the rate constants, it was found that $k_{\mathrm{TST}}<$ $k_{\text {expt }}$ but that lowering the barrier height (by an average of 4.7 $\mathrm{kJ} / \mathrm{mol}$ for the four reactions) yields calculated rate constants that are in excellent agreement with experiment at all temperatures.

Acknowledgment. The authors acknowledge the Materials Directorate, AFRL, and the ASC/MSRC supercomputer center for providing the computational and other resources for this work. Two of the authors thank the Robert A. Welch Foundation [Grants B-1174 (P.M.) and B-657 (M.S.)], the UNT Faculty Research Fund, and the Materials Directorate, AFRL, for financial support. The authors also thank Dr. H. B. Schlegel for helpful discussions on internal rotor partition functions and for furnishing his derived expressions for $Q_{\mathrm{HR}}$ prior to publication.

\section{References and Notes}

(1) Banks, R. E. J. Fluorine Chem. 1994, 67, 193.

(2) Andersen, S. O.; Metchis, K. L.; Rubenstein, R. In Halon Replacements; Miziolek, A. W., Tsang, W., Eds.; ACS Symp. Ser. 611; American Chemical Society: Washington, DC, 1995; Chapter 2.

(3) Rowland, F. S. Environ. Sci. Technol. 1991, 25, 622.

(4) Wallington, T. J.; Schneider, W. F.; Nielsen, O. J.; Sehested, J.; Worsnop, D. R.; De Bruyn, W. J.; Shorter, J. A. In Halon Replacements; Miziolek, A. W., Tsang, W., Eds.; ACS Symp. Ser. 611: American Chemical Society: Washington, DC, 1995; Chapter 3.

(5) Grosshandler, W. L., Gann, R. G., Pitts, W. M., Eds. Evaluation of Alternative In-Flight Fire Suppressants for Full-Scale Testing in Simulated Aircraft Engine Nacelles and Dry Bays. NIST Special Publication 1994, 861 .

(6) Gaussian 92, Revision F.4: Frisch, M. J.; Trucks, G. W.; HeadGordon, M.; Gill, P. M. W.; Wong, M. W.; Foresman, J. B.; Johnson, B. G.; Schlegel, H. B.; Robb, M. A.; Replogle, E. S.; Gomperts, R.; Andres, J. L.; Raghavachari, K.; Binkley, J. S.; Gonzalez, C.; Martin, R. L.; Fox, D. J.; Defrees, D. J.; Baker, J.; Stewart, J. J. P.; Pople, J. A. Gaussian, Inc., Pittsburgh, PA, 1992.

(7) Gaussian 94, Revision A.1: Frisch, M. J.; Trucks, G. W.; Schlegel, H. B.; Gill, P. M. W.; Johnson, B. G.; Robb, M. A.; Cheeseman, J. R.; Keith, T. A.; Petersson, G. A.; Montgomery, J. A.; Raghavachari, K.; AlLaham, M. A.; Zakrzewski, V. G.; Ortiz, J. V.; Foresman, J. B.; Cioslowski, J.; Stefanov, B. B.; Nanayakkara, A.; Challacombe, M.; Peng, C. Y.; Ayala, P. Y.; Chen, W.; Wong, M. W.; Andres, J. L.; Replogle, E. S.; Gomperts, R.; Martin, R. L.; Fox, D. J.; Binkley, J. S.; Defrees, D. J.; Baker, J.; Stewart, J. J. P.; Head-Gordon, M.; Gonzalez, C.; Pople, J. A. Gaussian, Inc., Pittsburgh, PA, 1995.

(8) Curtiss, L. A.; Raghavachari, K.; Trucks, G. W.; Pople, J. A. J. Chem. Phys. 1991, 94, 7221.

(9) Curtiss, L. A.; Raghavachari, K.; Pople, J. A. J. Chem. Phys. 1993, 98, 1293.

(10) Curtiss, L. A.; Raghavachari, K.; Pople, J. A. J. Chem. Phys. 1995, $103,4192$.

(11) (a) Gonzalez, C.; Schlegel, H. B. J. Phys. Chem. 1989, 90, 2154. (b) $\mathbf{1 9 9 0 , 9 4 , 5 5 2 3 . ~}$

(12) Eyring, H. J. Chem. Phys. 1935, 35, 107.

(13) Hill, T. L. An Introduction to Statistical Thermodynamics; AddisonWesley Publishing Co.: Reading, MA, 1960; Chapter 9.

(14) Chase Jr., M. W.; Davies, C. A.; Downey, Jr., J. R.; Frurip, D. J.; McDonald, R. A.; Syverud, A. N. JANAF Thermochemical Tables, 3rd ed.; J. Phys. Chem. Ref. Data 1985, 14 (Suppl. 1).

(15) Ayala, P. Y.; Schlegel, H. B. J. Chem. Phys. 1998, 108, 2314.

(16) Truhlar, D. G. J. Comput. Chem. 1990, 12, 266.

(17) Lu, D.-H.; Truong, T. N.; Melissas, V. S.; Lynch, G. C.; Liu, Y.P.; Garrett, B. C.; Steckler, R.; Isaacson, A. D.; Rai, S. N.; Hancock, G. C.; Lauderdale, J. G.; Joseph, T.; Truhlar, D. G. Comput. Phys. Commun. 1992, 71, 235.

(18) Steckler, R.; Hu, W.-P.; Liu, Y.-P.; Lynch, G. C.; Garrett, B. C.; Isaacson, A. D.; Lu, D.-H.; Melissas, V. S.; Truong, T. N.; Rai, S. N.; 
Hancock, G. C.; Lauderdale, J.; Joseph, T.; Truhlar, D. G. POLYRATE, V. 6.5, University of Minnesota, Minneapolis, 1995.

(19) Eckart, C. Phys. Rev. 1930, 35, 1303.

(20) (a) Complete Basis Set Thermochemistry and Kinetics. Petersson, G. A. In Computational Thermochemistry: Prediction and Estimation of Molecular Thermodynamics; Irikura, K., Frurip, D., Eds.; ACS Symposium Series; American Chemical Society: Washington, DC, 1998; pp 237-266. (b) Malick, D. K.; Petersson, G. A.; Montgomery, J. A. J. Chem. Phys. 1998, $108,5704$.

(21) Berry, R. J.; Burgess, Jr., D. R. F.; Nyden, M. R.; Zachariah, M. R.; Schwartz, M. J. Phys. Chem. 1995, 99, 17145.

(22) G2 energies for the product radicals are as follows (in au): $\mathrm{CH}_{3}$, -39.745 084; $\mathrm{CH}_{2} \mathrm{~F},-138.892899 ; \mathrm{CHF}_{2},-238.056020 ; \mathrm{CF}_{3},-337.223707$.

(23) Bottoni, A.; Poggi, G.; Emmi, S. S. J. Mol. Struct.(THEOCHEM) 1993, 279, 299.

(24) Gonzalez, C.; McDouall, J. J. W.; Schlegel, H. B. J. Phys. Chem. 1990, 94, 7467.

(25) Truong, T. N.; Truhlar, D. G. J. Chem. Phys. 1990, 93, 1761.

(26) Dobbs, K. D.; Dixon, D. A.; Komornicki, A. J. Chem. Phys. 1993, 98,8852 .

(27) Melissas, V. S.; Truhlar, D. G. J. Chem. Phys. 1993, 99, 1013.

(28) Fu, Y.; Lewis-Bevan, W.; Tyrrell, J. J. Phys. Chem. 1995, 99, 630

(29) Dunlop, J. R.; Tully, F. P. J. Phys. Chem. 1993, 97, 11148.

(30) Fenimore, C. P.; Jones, G. W. J. Phys. Chem. 1961, 65, 2200.

(31) Sharkey, P.; Smith, I. W. M. J. Chem. Soc., Faraday Trans. 1993, $89,631$.

(32) Madronich, S.; Felder, W. Symp. Int. Combust. Proc. 1985, 20,
(33) Tully, F. P.; Ravishankara, A. R. J. Phys. Chem. 1980, 84, 3126.

(34) Davis, D. D.; Fischer, S.; Schiff, R. J. Chem. Phys. 1974, 61, 2213.

(35) Zellner, R.; Steinert, W. Int. J. Chem. Kinet. 1976, 8, 397.

(36) Vaghjiani, G. L.; Ravishankara, A. R. Nature (London) 1991, 350 406.

(37) Baulch, D. L.; Cobos, C. J.; Cox, R. A.; Esser, C.; Frank, P.; Just, Th.; Kerr, J. A.; Pilling, M. J.; Troe, J.; Walker, R. W.; Warnatz, J. J. Phys. Chem. Ref. Data 1992, 21, 411.

(38) Jeong, K.-M.; Kaufman, F. J. Phys. Chem. 1982, 86, 1808.

(39) Howard, C. J.; Evenson, K. M. J. Chem. Phys. 1976, 64, 197.

(40) Nip, W. S.; Singleton, D. L.; Cvetanovic, R. J. Can. J. Chem. 1979, $57,949$.

(41) Schmoltner, A. M.; Talukdar, R. K.; Warren, R. F.; Mellouki, A.; Goldfarb, L.; Gierczak, T.; McKeen, S. A.; Ravishankara, A. R. J. Phys. Chem. 1993, 97, 8976.

(42) Clyne, M. A. A.; Holt, P. M. Ber. Bunsen-Ges. Phys. Chem. 1979 75,582 .

(43) Talukdar, R.; Mellouki, A.; Gierczak, T.; Burkholder, J. B.; McKeen, S. A.; Ravishankara, A. R. J. Phys. Chem. 1991, 95, 5815.

(44) Nip, W. S.; Singleton, D. L.; Overend, R.; Paraskevopoulos, G. J. Phys. Chem. 1979, 19, 2440.

(45) Truhlar, D. G.; Kuppermann, A. J. Am. Chem. Soc. 1971, 93, 1840.

(46) At $293 \mathrm{~K}, \operatorname{KIE}\left(Q_{\text {trans }}\right)=1.2, \operatorname{KIE}\left(Q_{\text {rot }}\right)=1.8, \operatorname{KIE}\left(Q_{\text {vib }}\right)=0.7$, $\operatorname{KIE}\left(Q_{\mathrm{HIR}}\right)=1.0, \operatorname{KIE}(\Gamma)=1.7, \operatorname{KIE}(\mathrm{ZPE})=5.3$.

(47) For $\mathrm{CD}_{4}+\mathrm{OH},(\mathrm{ZPE})_{\mathrm{TS}}-(\mathrm{ZPE})_{\mathrm{RCT}}=8402 \mathrm{~cm}^{-1}-8651 \mathrm{~cm}^{-1}$ $=-249 \mathrm{~cm}^{-1}=-3.0 \mathrm{~kJ} \mathrm{~mol}^{-1}$. For $\mathrm{CH}_{4}+\mathrm{OH},(\mathrm{ZPE})_{\mathrm{TS}}-(\mathrm{ZPE})_{\mathrm{RCT}}=$ $10559 \mathrm{~cm}^{-1}-11147 \mathrm{~cm}^{-1}=-588 \mathrm{~cm}^{-1}=-7.0 \mathrm{~kJ} \mathrm{~mol}^{-1}$. 